\title{
ENSINO DE LÍNGUAS MINORITÁRIAS: UMA REVISÃO DE LITERATURA SOBRE O TALIAN
}

\author{
TEACHING MINORITY LANGUAGES: A LITERATURE \\ REVIEW ON TALIAN
}

\section{Ariela Fátima Comiotto*}

REsumo: Este trabalho apresenta uma revisão de literatura envolvendo o talian, uma língua minoritária brasileira que tomou forma a partir de distintos dialetos falados pelos imigrantes italianos. Embora o Brasil tenha recebido diversos imigrantes desde a chegada dos portugueses no século XVI, outras línguas existentes aqui, que não a portuguesa, não são valorizadas nas escolas, sendo estigmatizadas e pertencentes a classe de línguas minoritárias. Desse modo, houve a necessidade de investigar tal língua a fim de apontar as pesquisas da área e relacioná-las com as políticas de promoção da língua nos municípios que a cooficializaram. A revisão bibliográfica verificou que há diversos estudos que investigaram o talian, principalmente sob a perspectiva da sociolinguística. Em geral, observou-se que as ações de ensino dessa língua minoritária são frutos de ações individuais e não políticas municipais.

Palavras-chave: Talian. Línguas minoritárias. Políticas linguísticas educacionais.

Aвstract: This work presents a literature review of studies involving Talian, a Brazilian minority language spoken by Italian immigrants. Although Brazil has received several immigrants since the arrival of the Portuguese in the 16th century, languages other than Portuguese are seldom given any recognition in schools, being categorized as minority languages. Thus, further investigation on Talian has proved necessary in order to point out research in the area and relate them to current educational language policies. The literature review reveals that there are several studies that have investigated Talian, mainly under the perspective of sociolinguistics. It is observed that the teaching actions of this minority language are the result of individual actions and not municipal policies.

KEYwords: Talian. Minority languages. Educational language policies.

\footnotetext{
"Mestra em Linguística pela Universidade Federal de Santa Catarina. Doutoranda do Programa de Pós-Graduação em Linguística da Universidade Federal de Santa Catarina. Bolsista CAPES. E-mail: ariela.comiotto@gmail.com.
} 


\section{INTRODUÇão}

Ao longo dos mais de 500 anos, desde a chegada dos portugueses ao que hoje denominamos Brasil, houve um entrecruzamento de diversos povos, gerando uma identidade pluriétnica na formação da sociedade brasileira, como aponta Ferraz (2007). Em outras palavras, levando em conta que a chegada de um colonizador afeta não somente a língua de um povo, mas toda a sua cultura, o multilinguismo sempre esteve presente no território brasileiro; de início, com as diversas línguas indígenas já existentes no Brasil. A chegada dos portugueses introduz a língua portuguesa e, mais tarde, com o tráfico de escravos, chegam diversas línguas de origem africana. Séculos depois, com as políticas imigratórias incentivadas pelo governo brasileiro, imigrantes europeus e asiáticos trazem suas respectivas línguas, completando, assim, a pluralidade linguística no país. Porém, como aponta o autor, a imagem de unidade da língua nacional brasileira propiciou

uma imagem distorcida do panorama lingüístico do Brasil, como um enorme país monolíngüe, dominado pela língua portuguesa em toda a sua extensão, fato que esconde a sua realidade plurilíngüe, marcada pela coexistência de várias línguas com o português (FERRAZ, 2007, p. 44).

Vale ressaltar que, em complemento à afirmação de Ferraz, a língua portuguesa, assim como a língua inglesa, por exemplo, é chamada de língua nomeada, conforme atenta Li Wei em sua fala para um evento da Associação Brasileira de Linguística (Abralin). ${ }^{1} \mathrm{O}$ linguista diz que o termo trata de "conceitos político-culturais que são associados com uma ideologia de que cada nação possui apenas uma língua", o que culminou em uma noção de nação monolíngue (SCHOLL, 2020, p. 3).

No século XIX, o governo imperial brasileiro promoveu campanhas imigratórias incentivando a imigração europeia. Quando a imigração alemã iniciou, a partir do ano de 1824, esses imigrantes falantes de alemão que vieram para o Brasil organizaram-se aqui em pequenos grupos e, no interior destes, mantinham seus dialetos locais. ${ }^{2}$ Ferraz (2007) ressalta que, até 1937, nas colônias alemãs, todo o ensino se fazia em alemão.

Além da imigração alemã, a imigração italiana foi em número expressivo. Os italianos iniciaram a imigração no ano de 1875. Nos primeiros anos, esses imigrantes ocuparam a região Sul, além de que muitos se estabeleceram na região Sudeste a fim de trabalhar nas plantações de café. Grande parte desses imigrantes italianos que se estabeleceram na região mais ao sul do Brasil eram provenientes da região italiana do Vêneto e, portanto, falantes apenas do dialeto vêneto, ou seja, muitos deles não conheciam o italiano padrão.

\footnotetext{
${ }^{1}$ TRANS-ING Language and Cognition: Debates and Directions of Translanguaging Research. Conferência apresentada por Li Wei [s.l., s.n], 2020. 1 vídeo (57min 25s). Publicado pelo canal da Associação Brasileira de Linguística. Disponível em: https://www.youtube.com/watch?v=RxBBaRaO9jk\&ab_channel=Abralin. Acesso em: 10 maio 2021.

${ }^{2}$ Entende-se que "dialeto" se relaciona a uma variante da língua que envolve distribuição espacial, sociocultural e cronológica. E sabe-se que no Brasil há uma série de variedades dialetais identificadas social e geograficamente pela forma falada, e que, por conta disso, são atribuídos valores sociais que acabam por taxar uma língua com minoritária, ou seja, com menor prestígio. O termo "língua minoritária" já faz jus ao preconceito linguístico que ocorre (COELHO et al., 2015, p. 136; CARDOSO, 2010).
} 
Neste artigo, nos centraremos na língua minoritária falada pelos imigrantes italianos, o talian (melhor explanado na próxima seção). Embora o Brasil tenha recebido diversos imigrantes desde a chegada dos portugueses, outras línguas que não o português não são valorizadas nas escolas. Desse modo, realizamos uma revisão de literatura envolvendo o talian. Considerando, neste trabalho, como políticas linguísticas aquelas que têm "tradicionalmente se voltado para uma prática de caráter estatal-legislativo, debruçando-se, por exemplo, sobre a oficialização de línguas, a escolha de alfabeto para a representação gráfica de uma língua, a hierarquização formal das línguas [...]" (SEVERO, 2013, p. 451), selecionamos artigos, teses e dissertações que investigaram tal língua a fim de apontar os estudos da área e relacioná-los com as políticas de promoção da língua, caso haja políticas linguísticas educacionais que promovam o ensino do talian.

Este artigo está dividido da seguinte forma: abordaremos o que é o talian e a atual situação da língua no Brasil. Em seguida, apresentamos o método deste trabalho, uma revisão a partir da literatura publicada na área. Na penúltima seção, faremos uma breve discussão desse levantamento e, por fim, apresentamos as considerações finais desta pesquisa.

\section{TAlian - QUe LÍNGUa É ESSA?}

Conforme o Instituto do Patrimônio Histórico e Artístico Nacional (BRASIL, 2014), ao instaurar a língua talian no Inventário Nacional da Diversidade Linguística, ela passa a ser "uma das autodenominações para a língua de imigração falada no Brasil na região de ocupação italiana direta e seus desdobramentos desde 1875, em especial no nordeste do Rio Grande do Sul, Paraná, Santa Catarina, Mato Grosso e Espírito Santo" (BRASIL, 2014). É uma língua formada pelo contato de variedades do italiano com o português do Brasil. Sua origem linguística é o italiano e os dialetos falados no norte da Itália. De acordo com Miazzo (2011), o talian é uma língua que tomou forma a partir da fusão dos dialetos italianos pertencentes aos primeiros imigrantes italianos no sul do Brasil (que iniciaram a colonização a partir de 1875), com destaque para o dialeto vêneto. Cabe ressaltar que o talian é considerada uma língua minoritária. De acordo com Altenhofen (2013, p. 94), uma língua minoritária é "a modalidade de línguas ou variedades usadas à margem ou ao lado de uma língua (majoritária) dominante". Embora o português seja a língua majoritária, há diversas outras línguas faladas no território brasileiro e que são consideradas línguas minoritárias, tais como línguas indígenas, de imigração, de sinais ou afro-brasileiras são consideradas línguas minoritárias e variam, por exemplo, no número de falantes ou status social de cada língua (ALTENHOFEN, 2013).

Durante o Estado Novo, foram adotadas políticas linguísticas restritas. Foi proibido o uso das línguas de imigração. Tais medidas repercutiram na forma como os falantes de talian se comportavam em relação à própria língua. Até o início dos anos de 1930, o talian era a língua mais utilizada nas regiões de colonização italiana, em especial no Rio Grande do Sul. Conforme Luzzatto (2016), até mesmo os professores nas escolas não dominavam a língua portuguesa, assim, o talian era a língua utilizada em sala de aula. Porém, por volta do ano de 1930, a Nacionalização do Ensino proibiu a utilização de qualquer língua distinta do 
português. Essa política, que durou até o ano de 1945, impactou os falantes de talian, que se tornou uma língua estigmatizada, de silenciamento e vergonha (TIBOLLA, 2014). Foi apenas no ano de 1975, com o Centenário da Imigração Italiana, que se iniciou um movimento para valorizar a cultura e a língua dessas comunidades de descendentes.

No ano de 2010, o talian foi incluído no Inventário Nacional da Diversidade Linguística, com a atribuição do título de "Referência Cultural Brasileira", como podemos observar:

DECRETO 7.387, DE O9 DE DEZEMBRO DE 2010: A Ministra de Estado da Cultura, no uso de suas atribuições, de acordo com o artigo $3^{\circ}$ do Decreto no 7.387, de 09 de dezembro de 2010, e em decorrência da inclusão no Inventário Nacional da Diversidade Linguística, em og de setembro de 2014, confere o título de Referência Cultural Brasileira à língua denominada Talian (BRASIL, 2010).

Além da instauração do talian pelo decreto nacional, Santa Catarina e Rio Grande do Sul, decretaram a língua talian como patrimônio cultural e histórico dos estados, conforme seguem-se as leis:

LEI N ${ }^{\circ}$ 13.178, DE 10 DE JUNHO DE 2009: Declara integrante do patrimônio histórico e cultural do Estado o dialeto Talian, originado dos italianos e descendentes radicados no Rio Grande do Sul (RIO GRANDE DO SUL, 2009a).

LEI N ${ }^{\circ}$ 14.951, DE 11 DE NOVEMBRO DE 2009: Declara integrante do patrimônio histórico e cultural do estado o dialeto "Talian", originado dos italianos e descendentes radicados em Santa Catarina (SANTA CATARINA, 2009). ${ }^{3}$

Conforme apresenta o Quadro 1, há diversas cidades pertencentes a esses dois estados mencionados que co-oficializaram o talian à língua portuguesa, no sentido de herança cultural e incentivo ao conhecimento.

Quadro 1 - Cidades brasileiras onde o Talian é língua cooficial

\begin{tabular}{lll}
\hline Talian & Serafina Corrêa/RS (novembro 2009) & Ivorá/RS (23 março 2018_ \\
Flores da Cunha/RS (abril 2015) & Antônio Prado/RS \\
Bento Gonçalves/RS (junho 2016) & Camargo/RS \\
Parai/RS (2016) & Nova Pádua/RS \\
Nova Roma do Sul/RS (outubro 2015) & Guabiju/RS \\
Fagundes Varela/RS (junho 2016) & Nova Erechim/SC (agosto 2015) \\
Caxias do Sul/RS (outubro 2017) & Ipumirim/SC (2020) 14 municípios
\end{tabular}

Fonte: Ipol. Disponível em: http://ipol.org.br/lista-de-linguas-cooficiais-em-municipios-brasileiros. Acesso em: 14 maio 2021.

\footnotetext{
${ }^{3}$ Embora as leis promulgadas nos estados de Santa Catarina e Rio Grande do Sul utilizem o termo "dialeto", no Decreto 7.387/2010, em que o talian é determinado como Referência Cultural Brasileira, é utilizado o termo "língua". Não é nosso objetivo aqui discutir questões relacionadas aos conceitos de "língua" ou "dialeto", assim, optamos por considerar o talian como língua.
} 
Como podemos verificar, o talian está cooficializado em diversas cidades. Além disso, conforme dados dos Estudos do Grupo de Trabalho da Diversidade Linguística (BRASIL, 2014), órgão vinculado ao Instituto de Pesquisa Econômica Aplicada (IPEA), estima-se que 500 mil pessoas utilizem o talian no Brasil em diversas regiões do país, especialmente a região sul do Brasil.

Conforme observamos no Quadro 1, a primeira cidade a cooficializar o talian foi Serafina Corrêa (RS). A ata de discussão do "Processo de Co-Oficialização da Língua Talian" no município apresenta aspectos importantes para esta pesquisa, pois denota a preocupação em relação a quais medidas serão tomadas com vistas à manutenção e preservação da língua:

[...] como seria para levar avante essa língua após tomá-la co-oficial perante escolas, eventos, órgãos oficiais, necessidade de quadros de professores, já que o objetivo não é apenas a edição da Lei, mas ir além disso com ações que preservem mesmo o Talian.

[...] embora exista Lei Estadual declarando o Talian patrimônio histórico esse não se pode colocar na grade curricular, pois não está normatizado pelo Conselho Estadual de Educação. Além disso, a LDB determina que a formação se dê através de uma base comum e de uma parte diversificada incluído a partir da $5^{\mathrm{a}}$ seria uma língua estrangeira moderna escolhida pela comunidade escolar. Logo, existe dificuldade para inserir o Talian nas escolas pois não está reconhecida como língua estrangeira e não existe normatização frente ao Conselho Estadual, todavia o Talian pode ser trabalhado com projetos culturais, lingüísticos abertos a toda comunidade aproveitando turnos inversos da Escola (SERRAFINA CORRÊA, 2009, p. 4).

Destacamos a preocupação dos vereadores do município em não apenas cooficializar a língua, mas também investir em ações que a preservem. Por outro lado, o excerto do processo ilustra algumas das dificuldades encontradas para o ensino do talian nas escolas, como a formação de professores na área, além da questão de implementação de ensino da língua no ensino regular. Conforme o Dicionário de Termos Linguísticos, uma LE é a "[l]íngua não nativa do sujeito e por ele aprendida com maior ou menor grau de eficiência”. ${ }^{4}$ Considerando a definição de LE, não é possível de fato considerar o talian como uma LE, visto que a língua, em geral, é aprendida em casa, com pais ou familiares, principalmente na forma oralizada. Assim, dada as dificuldades para o ensino do talian em escolas regulares, nos questionamos: como se dá o ensino dessa língua nas escolas e quais são suas políticas de promoção? Para responder a essa pergunta, realizamos uma revisão de literatura dos estudos na área, que será descrita na seção seguinte.

${ }^{4}$ Disponível em: http://www.portaldalinguaportuguesa.org/?action=terminology\&act=view\&id=1962. Acesso em: 28 set. 2021. 


\section{As PESQUISAS SOBRE a LÍNGUA TALIAN No BRASIL}

Este artigo foi elaborado a partir de uma revisão de literatura. Para isso, buscamos trabalhos que investigaram o talian. A fim de verificar quais estudos já foram realizados sobre essa língua, pesquisamos o termo "talian" no Catálogo de Teses \& Dissertações da CAPES ${ }^{5}$ e encontramos 26 estudos no banco de dados. No entanto, após uma sondagem inicial, consideramos 24 estudos para este trabalho. ${ }^{6}$

Grande parte dos estudos realizados são da área da sociolinguística. Assim, a título de ilustração e curiosidade, apresentamos o Quadro 2 com os estudos e suas respectivas áreas de pesquisa envolvendo o talian como tema.

Quadro 2 - Levantamento dos estudos envolvendo o Talian

\begin{tabular}{|c|c|c|c|}
\hline ÁREA & $\begin{array}{c}\text { AUTOR E } \\
\text { ANO DE } \\
\text { PUBLICAÇÃO }\end{array}$ & $\begin{array}{l}\text { TÍTULO DO } \\
\text { TRABALHO }\end{array}$ & OBJETIVO \\
\hline Antropologia & $\begin{array}{l}\text { MOMBELLI } \\
\text { (1996) }\end{array}$ & $\begin{array}{l}\text { "Mi soi talian, gracia a } \\
\text { Dio": Identidade étnica } \\
\text { e separatismo no oeste } \\
\text { catarinense. }\end{array}$ & $\begin{array}{c}\text { Investigar a construção de uma } \\
\text { identidade italiana na região oeste do } \\
\text { Estado de Santa Catarina e sua relação } \\
\text { com um projeto político específico: a } \\
\text { criação de um novo Estado da Federação: } \\
\text { o Estado do Iguaçu (abrangendo o } \\
\text { oeste de Santa Catarina e o sudoeste do } \\
\text { Paraná). }\end{array}$ \\
\hline Educação & $\begin{array}{l}\text { DE MARCO } \\
(2009)\end{array}$ & $\begin{array}{l}\text { A trajetória e presença } \\
\text { do Talian e do dialeto } \\
\text { Trentino em Santa } \\
\text { Catarina: por uma } \\
\text { educação intercultural. }\end{array}$ & $\begin{array}{l}\text { Analisar o caminho percorrido pela } \\
\text { língua taliana e pelo dialeto Trentino } \\
\text { e suas relações com o ensino da língua } \\
\text { Italiana standard ou padrão, por meio } \\
\text { dos professores, alunos e principalmente } \\
\text { pelos seus falantes. }\end{array}$ \\
\hline
\end{tabular}

continua

\footnotetext{
${ }^{5}$ Disponível em: https://catalogodeteses.capes.gov.br, Acesso em: 5 maio 2021.

${ }^{6}$ Descartamos dois estudos encontrados na plataforma, um deles pelo fato de que o termo "talian" era parte do nome da autora do texto e não o tema da pesquisa. Além disso, um segundo estudo foi descartado por se tratar de pesquisa cujo tema principal era a elaboração de dicionário Hunsrückisch.
} 
continuação

\begin{tabular}{|c|c|c|c|}
\hline ÁREA & $\begin{array}{c}\text { AUTOR E } \\
\text { ANO DE } \\
\text { PUBLICAÇÃO }\end{array}$ & $\begin{array}{l}\text { TÍTULO DO } \\
\text { TRABALHO }\end{array}$ & OBJETIVO \\
\hline \multirow{6}{*}{$\begin{array}{l}\text { Letras - } \\
\text { Sociolinguística } \\
\text { e Dialetologia }\end{array}$} & $\begin{array}{l}\text { ARMILIATO } \\
(2010)\end{array}$ & $\begin{array}{l}\text { A comunicação no } \\
\text { Rádio e a preservação } \\
\text { de uma identidade } \\
\text { linguística regional: o } \\
\text { Talian. }\end{array}$ & $\begin{array}{l}\text { Descobrir os motivos pelos quais milhares } \\
\text { de pessoas sintonizam programas } \\
\text { radiofônicos transmitidos em talian na } \\
\text { Região da Serra Gaúcha. }\end{array}$ \\
\hline & BELONI (2015) & $\begin{array}{l}\text { Um estudo sobre a } \\
\text { fala e a cultura de } \\
\text { ítalo-descendentes em } \\
\text { Cascavel/PR }\end{array}$ & $\begin{array}{l}\text { Demonstrar o comportamento de alguns } \\
\text { ítalo-descendentes em Cascavel perante a } \\
\text { língua e a cultura de seus antepassados. }\end{array}$ \\
\hline & $\begin{array}{l}\text { BERNIERI } \\
(2017)\end{array}$ & $\begin{array}{l}\text { Crenças e atitudes } \\
\text { linguísticas em relação } \\
\text { a línguas minoritárias: } \\
\text { alemão em São Carlos/ } \\
\text { SC e italiano em } \\
\text { Coronel Freitas/SC }\end{array}$ & $\begin{array}{l}\text { Analisar crenças linguísticas de teuto- } \\
\text { brasileiros em relação ao alemão, em } \\
\text { São Carlos/SC, e de ítalo-brasileiros em } \\
\text { relação ao italiano (talian), em Coronel } \\
\text { Freitas/SC. }\end{array}$ \\
\hline & $\begin{array}{l}\text { BORTOLOTTO } \\
(2015)\end{array}$ & $\begin{array}{l}\text { O talian na fala dos } \\
\text { ítalo-brasileiros em } \\
\text { Chapecó/SC e Pato } \\
\text { Branco/PR: manutenção } \\
\text { e substituição dos } \\
\text { termos de parentesco. }\end{array}$ & $\begin{array}{c}\text { Descrever e analisar a manutenção e a } \\
\text { substituição dos termos de parentesco } \\
\text { do talian pelos termos de parentesco do } \\
\text { português (Pt.), na fala de informantes } \\
\text { ítalo-brasileiros em Chapecó/SC e Pato } \\
\text { Branco/PR; em contextos plurilíngues, } \\
\text { de contato linguístico do talian com } \\
\text { o português do Oeste de SC, com o } \\
\text { português do Sudoeste do PR, com o } \\
\text { português padrão e com o italiano. }\end{array}$ \\
\hline & $\begin{array}{l}\text { DAL PICOL } \\
\quad(2013)\end{array}$ & $\begin{array}{l}\text { A morfossintaxe na } \\
\text { oralidade do Vêneto } \\
\text { Sul-Rio-Grandense: } \\
\text { perfil dialetal de } \\
\text { comunidades rurais } \\
\text { da região da } 4^{a} \text { Légua, } \\
\text { Caxias do Sul/RS. }\end{array}$ & $\begin{array}{l}\text { Examinar, do ponto de vista da linguística } \\
\text { funcional, em que medida as estruturas } \\
\text { morfossintáticas na oralidade do dialeto } \\
\text { vêneto sul-rio-grandense, quando } \\
\text { comparadas às do dialeto vêneto italiano } \\
\text { e às da língua portuguesa, revelam } \\
\text { semelhanças e diferenças na formação } \\
\text { verbal do pretérito perfeito e em aspectos } \\
\text { do léxico, como a renovação vocabular. }\end{array}$ \\
\hline & $\begin{array}{c}\text { DALLEASTE } \\
(2016)\end{array}$ & $\begin{array}{l}\text { Crenças e atitudes } \\
\text { linguísticas: um } \\
\text { estudo da língua e } \\
\text { cultura italianas em } \\
\text { Matelândia/PR. }\end{array}$ & $\begin{array}{c}\text { A partir dos princípios teórico- } \\
\text { metodológicos da Sociolinguística } \\
\text { Variacionista, da Dialetologia e } \\
\text { por estudos de Crenças e Atitudes } \\
\text { linguísticas, se trata de um estudo sobre } \\
\text { as crenças e atitudes manifestadas por } \\
\text { falantes ítalo-descendentes, moradores } \\
\text { do município de Matelândia, situado na } \\
\text { região Oeste do Paraná. }\end{array}$ \\
\hline
\end{tabular}

continua 
continuação

\begin{tabular}{|c|c|c|c|}
\hline ÁREA & $\begin{array}{c}\text { AUTOR E } \\
\text { ANO DE } \\
\text { PUBLICAÇÃO }\end{array}$ & $\begin{array}{l}\text { TÍTULO DO } \\
\text { TRABALHO }\end{array}$ & OBJETIVO \\
\hline \multirow{5}{*}{$\begin{array}{l}\text { Letras - } \\
\text { Sociolinguística } \\
\text { e Dialetologia }\end{array}$} & $\begin{array}{c}\text { FESTUGATTO } \\
(2005)\end{array}$ & $\begin{array}{c}\text { Interferências da língua } \\
\text { talian no aprendizado } \\
\text { do espanhol: um estudo } \\
\text { de caso. }\end{array}$ & $\begin{array}{l}\text { Analisar os dados sobre a interferência } \\
\text { da língua talian no aprendizado de } \\
\text { espanhol, língua estrangeira, mais } \\
\text { especificamente sobre o emprego do tepe } \\
\text { no lugar da vibrante múltipla, à luz da } \\
\text { Teoria da Marcação Fonológica, baseada } \\
\text { em Restrições e Procedimentos de } \\
\text { Simplificação. }\end{array}$ \\
\hline & GUBERT (2012) & $\begin{array}{l}\text { Influências do italiano } \\
\text { no português brasileiro } \\
\text { de Vargeão/SC: um } \\
\text { estudo sobre variação } \\
\text { no nível fonético. }\end{array}$ & $\begin{array}{l}\text { Analisar alguns elementos característicos } \\
\text { da fala do povo da cidade de Vargeão/SC, } \\
\text { município colonizado por descendentes } \\
\text { de imigrantes da região de fala vêneta, } \\
\text { provindos do Rio Grande do Sul, } \\
\text { para descrever a variação fonética no } \\
\text { idioma local causada pelo bilinguismo } \\
\text { talian-português. }\end{array}$ \\
\hline & $\begin{array}{l}\text { HASSELSTRON } \\
(2018)\end{array}$ & $\begin{array}{l}\text { Línguas de imigração } \\
\text { em contato com o } \\
\text { português no oeste } \\
\text { catarinense: crenças e } \\
\text { atitudes linguísticas. }\end{array}$ & $\begin{array}{c}\text { Busca relacionar as crenças e as atitudes } \\
\text { linguísticas de bilíngues polono- } \\
\text { brasileiros, ítalo-brasileiros e teuto- } \\
\text { brasileiros e verificar semelhanças } \\
\text { e diferenças em suas percepções e } \\
\text { convicções sobre sua respectiva língua } \\
\text { minoritária. }\end{array}$ \\
\hline & $\begin{array}{l}\text { HONORIO } \\
(2016)\end{array}$ & $\begin{array}{l}\text { Descendentes de (i) } \\
\text { talianos de Cascavel/ } \\
\text { PR: língua e cultura } \\
\text { encobertas. }\end{array}$ & $\begin{array}{c}\text { Investigar, nas práticas discursivas, o } \\
\text { que há da língua e cultura do imigrado } \\
\text { italiano no contexto cascavelense, } \\
\text { mediante dados levantados por meio de } \\
\text { observação simples da citada comunidade } \\
\text { e entrevistas semiestruturadas, com } \\
\text { pessoas de três gerações: jovens, adultos } \\
\text { e idosos. }\end{array}$ \\
\hline & LODI (2020) & $\begin{array}{l}\text { Ghe zera una volta... O } \\
\text { ensino de talian como } \\
\text { língua adicional para } \\
\text { crianças: uma proposta } \\
\text { didática a partir da } \\
\text { contação de história. }\end{array}$ & $\begin{array}{l}\text { Investigar as potencialidades de uma } \\
\text { proposta didática, voltada ao ensino de } \\
\text { talian para crianças, a partir da contação } \\
\text { de história, para a aquisição e retenção de } \\
\text { vocabulário no referido idioma, por meio } \\
\text { da interação em sala de aula. }\end{array}$ \\
\hline
\end{tabular}

continua 
continuação

\begin{tabular}{|c|c|c|c|}
\hline ÁREA & $\begin{array}{c}\text { AUTOR E } \\
\text { ANO DE } \\
\text { PUBLICAÇÃO }\end{array}$ & $\begin{array}{l}\text { TÍTULO DO } \\
\text { TRABALHO }\end{array}$ & OBJETIVO \\
\hline \multirow{6}{*}{$\begin{array}{l}\text { Letras - } \\
\text { Sociolinguística } \\
\text { e Dialetologia }\end{array}$} & MATOZO (2018) & $\begin{array}{l}\text { Crenças e atitudes } \\
\text { linguísticas de ítalo- } \\
\text { descendentes no } \\
\text { contato português/ } \\
\text { talian: contexto urbano } \\
\text { e rural de Chapecó/SC. }\end{array}$ & $\begin{array}{c}\text { Analisar dados linguísticos que indicam } \\
\text { crenças e atitudes linguísticas em relação } \\
\text { ao PT-RS e ao Talian nas comunidades } \\
\text { urbana e rural de Chapecó/SC. }\end{array}$ \\
\hline & PANIZ (2005) & $\begin{array}{l}\text { A fonologia do talian, o } \\
\text { vêneto-rio-grandense } \\
\text { falado na cidade de } \\
\text { Nova Roma do Sul, } \\
\text { sob a luz da teoria da } \\
\text { otimidade. }\end{array}$ & $\begin{array}{l}\text { Estudo do sistema fonológico } \\
\text { consonantal do Talian, ou Vêneto Rio- } \\
\text { grandense, também conhecido como o } \\
\text { Vêneto Brasileiro; o estudo centrou-se } \\
\text { especificamente no Talian falado na } \\
\text { cidade de Nova Roma do Sul. }\end{array}$ \\
\hline & PERTILE (2009) & $\begin{array}{c}\text { O talian entre o } \\
\text { italiano-padrão e o } \\
\text { português brasileiro: } \\
\text { manutenção e } \\
\text { substituição lingüística } \\
\text { no Alto Uruguai } \\
\text { gaúcho. }\end{array}$ & $\begin{array}{c}\text { Dentre os objetivos, destaca-se o de } \\
\text { contribuir para uma revisão do conceito } \\
\text { de substituição e morte linguística e } \\
\text { aportar possibilidades de implantação } \\
\text { e implementação de uma política } \\
\text { linguística voltada às necessidades da } \\
\text { região. }\end{array}$ \\
\hline & $\begin{array}{l}\text { RODRIGUES } \\
\text { (2015) }\end{array}$ & $\begin{array}{l}\text { Mi parlo taliàn: análise } \\
\text { sociolinguística do } \\
\text { bilinguismo português- } \\
\text { dialeto italiano no } \\
\text { município de Santa } \\
\text { Teresa/ES. }\end{array}$ & $\begin{array}{l}\text { Investigar o atual estágio de manutenção } \\
\text { das variedades dialetais da Itália } \\
\text { setentrional no município de Santa } \\
\text { Teresa, localizado na região serrana do } \\
\text { Espírito Santo. }\end{array}$ \\
\hline & TIBOLLA (2014) & $\begin{array}{l}\text { 'Me tocou virar tudo': } \\
\text { cicatrizes discursivas } \\
\text { em narrativas de } \\
\text { descendentes de } \\
\text { imigrantes italianos. }\end{array}$ & $\begin{array}{l}\text { Analisar por meio de narrativas pessoais, } \\
\text { pelos traços de memória, cicatrizes } \\
\text { discursivas decorrentes dos processos de } \\
\text { identificação e interdição na constituição } \\
\text { linguística de descendentes de imigrantes } \\
\text { italianos. }\end{array}$ \\
\hline & ZORTEA (2019) & $\begin{array}{l}\text { Marcadores discursivos } \\
\text { do talian no programa } \\
\text { radiofônico Un } \\
\text { Pochetin Dela Itàlia em } \\
\text { Caibi, Santa Catarina. }\end{array}$ & $\begin{array}{l}\text { Investigar o uso de marcadores } \\
\text { discursivos no talian no programa } \\
\text { radiofônico Un Pochetin dela Itàlia, } \\
\text { transmitido, aos domingos, pela } \\
\text { Rádio Caibi 96.7 FM e pela Internet, do } \\
\text { município de Caibi/SC. }\end{array}$ \\
\hline
\end{tabular}

continua 
conclusão

\begin{tabular}{|c|c|c|c|}
\hline ÁREA & $\begin{array}{c}\text { AUTOR E } \\
\text { ANO DE } \\
\text { PUBLICAÇÃO }\end{array}$ & $\begin{array}{l}\text { TÍTULO DO } \\
\text { TRABALHO }\end{array}$ & OBJETIVO \\
\hline $\begin{array}{c}\text { Letras } \\
\text { - Psicolinguística }\end{array}$ & $\begin{array}{l}\text { COMIOTTO } \\
(2020)\end{array}$ & $\begin{array}{l}\text { Te parli piú talian ou } \\
\text { português? O fenômeno } \\
\text { de code-switching em } \\
\text { falantes bilíngues de } \\
\text { língua de herança } \\
\text { sob a abordagem } \\
\text { psicolinguística. }\end{array}$ & $\begin{array}{l}\text { Verificar se há ocorrência de code-switching } \\
\text { (CS) na produção oral dos bilíngues } \\
\text { do par português-talian, verificar qual } \\
\text { categoria do CS é mais produzida nesse } \\
\text { grupo e verificar se a alternância de } \\
\text { línguas gera custo de processamento. }\end{array}$ \\
\hline Turismo & ZANELLA (2017) & $\begin{array}{l}\text { Relações entre turismo } \\
\text { de experiência e } \\
\text { patrimônio cultural } \\
\text { imaterial: um estudo } \\
\text { sobre as experiências } \\
\text { memoráveis do filò } \\
\text { talian. }\end{array}$ & $\begin{array}{l}\text { Analisar o Filò Talian, costume dos } \\
\text { imigrantes italianos, como Patrimônio } \\
\text { Cultural Imaterial sob a perspectiva do } \\
\text { Turismo de Experiência. }\end{array}$ \\
\hline
\end{tabular}

Fonte: Elaboração própria.

O Quadro 2 apresenta as 21 teses ou dissertações que trazem o estudo do talian como tema principal. Como podemos observar, grande parte dos estudos envolvendo a língua se situam no campo da sociolinguística, totalizando 17 estudos. Pontuamos algumas informações relevantes apresentadas em alguns dos trabalhos mencionados.

Tibolla (2014) verificou que o talian é visto com estigmatização, mas, ao mesmo tempo, também é reconhecido como uma língua de aconchego que constitui os sujeitos linguisticamente, ou seja, como língua vinculada ao lar pelos falantes. Em sua pesquisa, Pertile (2009) conclui que são nos ambientes rurais (isto é, mais afastados dos centros urbanos) que se concentram os maiores índices de falantes de talian. Além disso, os resultados da pesquisa apontaram que há um incentivo e apreço pelo conhecimento da língua italiana standard, embora ocorra um movimento de manutenção do talian, como fator de identidade, conhecimento e culto às origens (PERTILE, 2009).

Já Rodrigues (2015) verificou que há uma substituição linguística do talian para o português. Para a autora, a escola, os meios de comunicação, as instituições públicas, por exemplo, são locais em que o uso da língua minoritária não é aceita, o que contribui para o desaparecimento da língua. Dal Picol (2013) é incisiva e afirma que "[...] as gerações mais jovens estão abandonando a fala dialetal. [...] O progressivo abandono do dialeto é visível. Sua extinção parece ser uma questão de tempo" (DAL PICOL, 2013, p. 104). Diante desse cenário, as políticas de cooficialização do talian e principalmente seu incentivo através do ensino se tornam fundamentais para a manutenção e preservação da língua. 
Destacamos que há diversos artigos publicados em revistas e periódicos que também investigaram o talian. Entretanto, para este trabalho, nos limitamos a fazer o levantamento a partir de teses e dissertações publicadas no Brasil. ${ }^{7}$ Ressaltamos dois trabalhos que trataram do ensino do talian na escola em suas pesquisas: De Marco (2009) e Lodi (2020).

De Marco (2009) apresenta como objetivos de sua pesquisa: (a) analisar a presença do talian (Concórdia) e do dialeto trentino (Rodeio) em Santa Catarina; (b) realizar uma análise histórica e sociolingüística do talian e do dialeto trentino; (c) investigar como ocorre a relação do ensino da língua italiana standard através dos professores e alunos e a relação com as línguas de imigração presentes nas comunidades e seus falantes; e (d) dar visibilidade aos outros falares de Santa Catarina que não o português, a fim de que não se percam. Nas duas cidades pesquisadas, há o ensino de italiano padrão ou standard na rede municipal de ensino. Além disso, os entrevistados declaram acreditar numa possível perda, tanto do dialeto trentino como do talian. A autora aponta que, assim como aconteceu na cidade de Rodeio, a Secretaria Municipal de Educação de Concórdia apoia o ensino do Italiano standard nas escolas públicas municipais, segundo o artigo 26 da Lei de Diretrizes e Base (LDB) de 1996. Como a autora destaca,

[...] até o presente momento, nos municípios pesquisados, nem o Talian e nem o dialeto Trentino despertaram a atenção dos órgãos competentes, como aspecto cultural e não há de fato algum projeto, nos campos de pesquisa, que tenha como objetivo a manutenção dessas línguas de imigração e, tampouco das entidades que se apropriam do discurso da preservação da cultura. Existem algumas iniciativas particulares como as mencionadas no decorrer do trabalho, mas são iniciativas isoladas (DE MARCO, 2009, p. 136).

A autora ressalta também que, tanto em Concórdia quanto em Rodeio, existe uma parcela da população que não diferencia seus falares (talian e dialeto trentino) em relação à língua italiana standard. Assim, muitos acreditam que o talian e o italiano padrão são uma língua só.

Destacamos também a pesquisa conduzida por Lodi (2020, p. 11) que teve por "objetivo investigar as potencialidades de uma proposta didática, voltada ao ensino de talian para crianças, a partir da contação de história, para a aquisição e retenção de vocabulário no referido idioma, por meio da interação em sala de aula". Chamou a atenção por ser o único estudo (dentre nossas investigações) que trabalha com uma proposta pedagógica na educação básica, especificamente na cidade de Camargo/RS. ${ }^{8}$

\footnotetext{
${ }^{7}$ Há um trabalho intitulado I piccoli signori: bilingüismo italo-português e apagamento do talian em Viadutos (RS) (PIOVESAN, 2007), que não está incluído no Quadro 2, pois não foi possível acessar de maneira remota o referido trabalho.

${ }^{8}$ Não foi possível encontrar a ata da sessão de cooficialização do talian na câmara de vereadores da cidade a fim de verificar quais foram os pontos levantados, bem como desafios para a promoção da língua no município.
} 
Outro ponto interessante se refere à proposta de ensino de talian como língua adicional (LA) para crianças. Como é apontado pela autora,

[n] esse contexto, o ensino da LA, que considera o conhecimento e a Li do aprendiz, vai além de simplesmente ensinar a estrutura da língua ou palavras isoladas; esse aprendizado deve trazer, para aquele que está aprendendo, diferentes possibilidades de agir no mundo, por meio de múltiplas práticas sociais. Nessa perspectiva, o aprendizado de uma LA, que pode ter diferentes funções na vida do indivíduo, passa a ser, também, um direito que amplia suas possibilidades de exercício da cidadania. Dessa forma, parece-nos que LA seria o conceito mais adequado a ser utilizado quando falarmos do ensino do talian para crianças, no município de Camargo, pois o contato deles com esse idioma vem a acrescentar um conhecimento a partir da língua materna que todos têm em comum, o português (LODI, 2020, p. 26).

Conforme a autora, com o intuito de resgatar e manter viva a língua da imigração e colonização italiana, no ano de 2017 ,

através da Lei Municipal ${ }^{\circ}$ 1798/2017, o Poder Público Municipal instituiu o Talian como língua cooficial do município, comprometendo-se a promover ações e eventos que garantam a difusão cultural e a manutenção e o resgate da língua, especialmente a falada (LODI, 2020, p. 11).

Segundo Lodi (2020), foi instaurado o Projeto Ritorno a le orígine, que contempla crianças do pré-escolar da educação infantil, até o quinto ano do ensino fundamental em formato de oficina nas escolas municipais. Entretanto, como a autora destaca,

cabe registrar que as oficinas, desde 2017, são desenvolvidas com certa informalidade. Não há um projeto pedagógico ou um plano de trabalho objetivando especificamente o ensino de Talian para crianças (ETC), assim como não há professores com qualificação acadêmica para tal (LODI, 2020, p. 12).

No município pesquisado, Camargo/RS,

[a] oficina é ofertada semanalmente em três de quatro escolas municipais existentes em Camargo. Há uma escola de educação infantil em turno integral, com crianças de seis meses a quatro anos que não recebe o projeto de ensino de talian; outra escola, também de educação infantil, compreendendo crianças de quatro a seis anos, no turno da tarde, na qual o projeto é realizado com a turma do pré-escolar. Existem duas escolas de ensino fundamental, uma localizada na área urbana, com turmas de primeiro a terceiro anos nos turnos da manhã e da tarde, 
e outra, de ensino fundamental multisseriada, localizada no interior do município. Essa escola, por estar distante das escolas específicas, atende também uma turma de educação infantil. Em ambas as escolas de ensino fundamental ocorre a oficina de talian, em todas as turmas (LODI, 2020, p. 23).

A autora também pontua que o professor responsável pelas oficinas de talian não possui formação pedagógica específica (entretanto, as crianças o consideram como professor), mas é fluente na língua e responsável por programas de rádio em talian.

Retomando a proposta do estudo de Lodi (2020, p. 94), cujo objetivo foi o de "investigar as potencialidades de uma proposta didática, voltada ao ensino de talian para crianças a partir da contação de história, por meio da interação em sala de aula, focalizando a aquisição e retenção de vocabulário desse idioma", a autora conclui argumentando que as atividades finais se mostraram satisfatórias, pois as crianças foram capazes de utilizar o talian nos gêneros textuais trabalhados ao longo das oficinas.

\section{O QUE SABEMOS SOBRE ENSINO DO TALIAN}

A cooficialização do talian em nada altera a oficialidade da língua nacional (português), no sentido de ser uma segunda língua. Sequer a Língua Brasileira de Sinais (Libras), também considerada uma língua minoritária, tem essa colocação, apesar de a Lei 10.436 (BRASIL, 2002) considerá-la como "meio legal de comunicação e expressão" em âmbito federal. A promulgação da Lei n 2615 (RIO GRANDE DO SUL, 2009a) dá ao talian apenas um status de incentivo ao seu conhecimento no município.

Apesar de estudos como o de Lodi (2020), que continua disseminando o talian na escola, mesmo que a título de oficina, e o de Balthazar e Perin Santos (2020) (detalhado mais adiante), que apresentam um aparato de material didático para o ensino do talian como língua de herança, segundo os Parâmetros Nacionais Curriculares brasileiros (BRASIL, 1997), o mais próximo de uma política linguística a que se chega é a permissão de ensino da língua italiana como língua estrangeira (LE), em detrimento do ensino de outras línguas estrangeiras como o inglês e o espanhol, por exemplo. Nesse caso, os alunos residentes em regiões de colonização italiana têm a possibilidade dessa escolha. No entanto, já vimos que ensino de italiano como LE não é o mesmo que ensino de talian, pois as línguas estão em situações de ensino e aprendizado diferentes.

Embora existam poucos registros de casos de ensino de talian, há projetos em andamento que incentivam a sua aprendizagem, manutenção e difusão. Um dos meios encontrados para a expansão do talian se dá através dos Difusores do Talian. A associação de difusores do talian foi criada no ano de 2008 e sua sede é em Serafina Corrêa/RS, cidade conhecida como 
capital do talian. É constituída principalmente por escritores, colunistas de jornais, professores, pesquisadores da língua, entre outros. A associação conta com pessoas de variadas profissões em distintos estados, como Rio Grande do Sul, Santa Catarina, Paraná e Mato Grosso. Os Difusores do Talian ministram cursos de formação, preservação e difusão da língua. Na revisão de literatura, podemos observar que há poucos relatos de intervenções pedagógicas em talian, sendo que a única encontrada foi em formato de oficina e não no currículo das escolas. Além disso, uma pesquisa pelos sites de notícias mostra que existem outras intervenções que visam ao ensino de talian em cidades de colonização italiana no sul do Brasil. ${ }^{9}$

Como citado anteriormente, destacamos agora o trabalho de Balthazar e Perin Santos (2020). No artigo, intitulado Material didático para o ensino de Talian como língua de herança no Brasil, as autoras chamam a atenção para a especificidade do ensino de línguas de herança.

[u]ma implicação relevante ao entender Talian como língua de herança no Brasil diz respeito a nós, pesquisadores brasileiros. A responsabilidade da produção, da análise e do ensino, nesta visão, está relacionada a professores e linguistas brasileiros. Se defendemos a língua Talian como língua que nasce em terras brasileiras, somos nós, linguistas do Brasil engajados com produção de materiais didáticos e metodologia de ensino os responsáveis por esta tarefa. Esse posicionamento está alinhado com a perspectiva da produção de materiais didáticos específicos para públicos específicos, pois isso permite a adequação das propostas de ensino às necessidades dos alunos e à realidade sociocultural em que eles circulam (BALTHAZAR; PERIN SANTOS, 2020, p. 862).

Esse é um ponto fundamental, pois, como apontado na discussão na câmara de vereadores de Serrafina Corrêa, o talian não é uma língua estrangeira e, dessa forma, não poderia ser visto e ensinado como tal. Para as autoras, o talian é uma língua de herança. Conforme Montrul (2016), o termo língua de herança (LH) surgiu no Canadá na década de 1970 para se referir às línguas minoritárias faladas naquele país. A palavra "herança" se refere a algo adquirido desde o nascimento e transmitido de geração em geração. Em geral, as línguas minoritárias são aquelas utilizadas por grupos etnolinguísticos minoritários e podem ou não ter status cooficial. Esses grupos etnolinguísticos podem representar uma minoria demográfica

\footnotetext{
' INICIA PROJETO 'TALIAN: PERSPECTIVAS E AÇÕES' NAS ESCOLAS DE FLORES DA CUNHA, RS. IPHOL. Disponível em: http://ipol.org.br/inicia-projeto-talian-perspectivas-e-acoes-nas-escolas-de-flores-da-cunha-rs/. Acesso em: 18 maio 2021.

PROJETO DE ENSINO DA LÍNGUA TALIAN, IMPLEMENTADO EM CAMARGO, COLHE BONS FRUTOS. TUA RÁDIO. Disponível em: http://www.tuaradio.com.br/Tua-Radio-Alvorada/noticias/cultura/29-03-2018/projeto-de-ensino-da-lingua-talian-implementado-em-camargo-colhe-bos-frutos. Acesso em: 18 maio 2021.

GARIBALDI FORMA ALUNOS NO DIALETO TALIAN. LEOUVE. Disponível em: https://leouve.com.br/garibaldi-forma-alunos-no-dialeto-talian/. Acesso em: 18 maio 2021.

PROJETO DE EXTENSÃO “LÍNGUA TALIAN" CTISM - UFSM. Disponível em: https://www.ufsm.br/unidades-universitarias/ctism/talian-lingua-talian/. Acesso em: 18 maio 2021.
} 
ou, ainda, serem formados por uma população numerosa, mas considerados minorias em virtude de seu status social, cultural e político mais baixo, relacionado a fatores que cercam a imigração ou a colonização (MONTRUL, 2016). Ainda segundo Montrul (2016), os falantes de língua de herança são os indivíduos que adquirem uma língua minoritária no ambiente familiar, mas que, ao mesmo tempo, adquirem a língua majoritária do país em que vivem. Neste caso, o talian é considerado uma LH, visto que seus falantes a adquirem em situações familiares, isto é, o talian é transmitido de geração em geração principalmente pelos familiares. Além disso, o talian é utilizado em ambientes informais, como no âmbito familiar ou entre vizinhos, por exemplo.

Os falantes de língua de herança também apresentam variabilidade quanto aos níveis de proficiência. Enquanto alguns falantes podem se comunicar na LH com outros membros da sociedade, outros utilizam a LH apenas no ambiente familiar (MONTRUL, 2016, p. 45). No caso do talian, embora seja pouco usado na escrita, seu uso oral não se restringe às situações familiares. Nas zonas rurais dos municípios das cidades em que é cooficializado, é possível observar diversos falantes utilizando o talian com vizinhos, conhecidos, no comércio, em alguns tipos de trabalho, por exemplo.

Retomando o trabalho proposto por Balthazar e Perin Santos (2020), as autoras argumentam que produzir um material para o ensino de uma língua de herança as colocou diante de desafios, visto que há poucos estudos com essa finalidade. A diferença desse estudo é que o material foi pensado não apenas para crianças em sala de aula, mas também considerava pessoas com diferentes perfis, tais como:

a) aulas de Talian para quem já sabe a língua, ou falava na infância e quer relembrá-la, ou ainda, para quem deseja aprendê-la; b) aulas de italiano standard em qualquer nível nas quais o professor queira apresentar aos alunos (descendentes de italianos ou não) uma língua de base vêneta e originada no Brasil; c) encontros entre pessoas que consideram para si o Talian como língua de herança, entre outros (BALTHAZAR; PERIN SANTOS, 2020, p. 870).

Outro ponto que merece destaque é em relação à modalidade oral de ensino. Embora existam gramáticas, livros e dicionários em talian, a língua é essencialmente utilizada na modalidade oral pelos falantes. Assim, as autoras do material de ensino propõem atividades comunicativas aos alunos. Além disso, o material didático para ensino de talian desenvolvido pelas autoras segue o formato de unidades didáticas que envolvem temas como a língua, a família, a religiosidade, a culinária e o trabalho. Por fim, as autoras apresentam algumas dessas unidades didáticas desenvolvidas. Não há menção aos resultados dessas oficinas.

Com base nos relatos dos artigos e trabalhos publicados, observamos que as iniciativas de ensino de talian partem muito mais de projetos de pesquisadores do que do poder público 
estadual ou municipal. Entendemos que são propostas muito válidas, com objetivos diversos que ultrapassam o ensino e chegam ao ponto da preocupação com a língua, de forma a não deixá-la extinguir. Porém, não se pode ficar apenas nessa dinâmica. Para fortalecimento do ensino e disseminação do talian, ainda se faz necessária a qualificação dos profissionais que a ensinam, sobretudo uma política que aplique proficiência nessa língua, como feito com línguas estrangeiras, como inglês e espanhol, por exemplo. Até o momento, ainda não temos qualquer programa de proficiência para o talian.

Consideramos que há a necessidade de uma política linguística educacional que possibilite capacitação aos profissionais de forma a fazer uso dessa variedade da língua para o ensino, não apenas como o centro do aprendizado, mas como ferramenta de ensino, vide exemplos de comunidades indígenas que possuem suas línguas tradicionais (também línguas minoritárias) e que podem aprender diversidade de saberes através de sua própria língua, sem necessariamente depender apenas da língua portuguesa.

\section{Conclusão}

Este artigo se propôs a fazer uma revisão de literatura sobre o ensino do talian no Brasil. Observa-se que diversas cidades dos estados de Santa Catarina e Rio Grande do Sul cooficializaram o talian, há também leis estaduais que instauram a língua como patrimônio cultural. Entretanto, nos municípios pesquisados, há poucas políticas que incentivem a promoção e o ensino da língua nos municípios por parte do poder público.

De toda forma, o português continua enraizado como língua nomeada, de prestígio e dominante, sobretudo porque no Brasil ainda permanecem os apagamentos por cuja atenção gritam as línguas minoritárias. Dessa forma, o risco de saltar do apagamento à extinção de uma língua permanece. Além disso, estudos demostraram que o ensino do italiano standard nas escolas é visto com prestígio pelos entrevistados nas pesquisas (DE MARCO, 2009; PERTILE, 2009), embora o talian seja considerado como língua de aconchego pelos seus falantes (TIBOLLA, 2014). Dessa forma, observamos que, em geral, os próprios falantes do talian não percebem a importância do ensino e preservação da língua para uso local.

Outro ponto importante se refere à implementação do ensino da língua nas escolas. $O$ talian não é uma língua estrangeira, visto que, apesar de ter suas bases nos dialetos italianos, nasceu no Brasil. Assim, não pode ser agregado ao currículo escolar como língua estrangeira moderna. Alguns municípios, como Serrafina Corrêa e Camargo (ambos no RS), adotaram aulas no contraturno ou projetos de promoção e ensino da língua para a sua manutenção, o que pode ser uma alternativa viável.

Considerar o talian como uma língua de herança, tal como propuseram Balthazar e Perin Santos (2020), é uma alternativa para pensar em processos de ensino e aprendizagem 
em LH, quais são as implicações, quais conteúdos são relevantes e quais métodos são os mais indicados nesse caso, por exemplo. Porém, cabe ressaltar que não há um processo de formação de professores em talian. Não há graduação na língua, tampouco um sistema de avaliação de proficiência em línguas minoritárias orais. Assim, uma questão que pode ser abordada em estudos futuros é: como ensinar uma língua oral em sala de aula?

Ainda que em passos lentos, a promulgação de leis que cooficializem o talian contribuem para o reconhecimento e a importância da língua, mas não é o suficiente. São necessárias políticas educacionais efetivas de promoção e ensino do talian nas escolas, bem como para outras pessoas que estejam interessadas em aprender a língua. Assim, esperamos que esta pesquisa sirva de aviso, de cuidado e principalmente de roteiro para novos estudos que possibilitem mais reflexões sobre políticas linguísticas educacionais envolvendo o ensino ou o uso do talian.

\section{REFERÊNCIAS}

ALTENHOFEN, Cléo. Bases para uma política linguística das línguas minoritárias no Brasil. In: NICOLAIDES, C.; SILVA, K. A.; TILIO, R.; HILSDORF, C. (Orgs). Política e Políticas Linguísticas. Campinas, SP: Pontes Editores, 2013.

ARMILIATO, Tales Giovani. A comunicação no rádio e a preservação de uma identidade linguística regional: o Talian. Dissertação (Mestrado em Letras, Cultura e Regionalidade) Faculdade de Letras, Universidade de Caxias do Sul. Caxias do Sul, 2010.

BALTHAZAR, Luciana Lanhi; PERIN SANTOS, Jovania Maria. Material didático para ensino de Talian como língua herança no Brasil. Revista X, v. 15, n. 6, p. 859-882, 2020. Disponível em: https://revistas.ufpr.br/revistax/article/view/76820/42246. Acesso em: 18 maio 2021.

BELONI, Wânia Cristiane. Um estudo sobre a fala e a cultura de italodescendentes em Cascavel/PR. Mestrado (em Letras) - Centro de Educação, Comunicação e Artes, Universidade Estadual do Oeste do Paraná, Campus de Cascavel. Cascavel, 155 f., 2015.

BERNIERI, Simone Raquel. Crenças e atitudes linguísticas em relação a línguas minoritárias: alemão em São Carlos/SC e italiano em Coronel Freitas/SC. Mestrado (em Estudos Linguísticos) - Programa de Pós-Graduação em Estudos Linguísticos, Universidade Federal da Fronteira Sul. Chapecó, 185 f., 2017.

BORTOLOTTO, Paula Cristina Merlo. $O$ talian na fala dos ítalo-brasileiros em Chapecó - SC e Pato Branco - PR: manutenção e substituição dos termos de parentesco. Mestrado (em Estudos Linguísticos) - Programa de Pós-Graduação em Estudos Linguísticos, Universidade Federal da Fronteira Sul. Chapecó, 187 f., 2015. 
BRASIL. Lei $\mathbf{n}^{\mathbf{0}}$ 10.436, de 24 de abril de 2002. Dispõe sobre a Língua Brasileira de Sinais - Libras e dá outras providências. Disponível em: http://www.planalto.gov.br/ccivil_03/leis/2002/lio436. htm. Acesso em: 16 maio 2021.

BRASIL. Decreto 7.387 de 09 de dezembro de 2010: Institui o Inventário Nacional da Diversidade Linguística e dá outras providências. 2010.

BRASIL. Certidão Talian. Instituto do Patrimônio Histórico e Artístico Nacional. Brasília, DF: Ministério da Cultura, 2014.

BRASIL, Ministério da Educação. Parâmetros Curriculares Nacionais para o Ensino Fundamental. Brasília, MEC/SEF, 1997.

CARDOSO, Susana Aline. Geolinguística: tradição e modernidade. São Paulo: Parábola, 2010.

COELHO, Izete Lehmkuhl; GÖRSKI, Edair Maria; NUNES DE SOUZA, Christiane Maria; MAY, Guilherme Henrique. Para conhecer sociolinguística. São Paulo: Contexto, 2015. (Coleção Para Conhecer Linguística).

COMIOTTO, Ariela Fátima. Te parli piú talian ou português? $\mathbf{O}$ fenômeno de code-switching em falantes bilíngues de língua de herança sob a abordagem psicolinguística. Mestrado (em Linguística) - Centro de Comunicação e Expressão, Universidade Federal de Santa Catarina. Florianópolis, SC, 125 f., 2020.

DALLEASTE, Ana Paula. Crenças e atitudes linguísticas: um estudo da língua e cultura italianas em Matelândia/PR. Mestrado (em Letras) - Centro de Educação, Comunicação e Artes, Universidade Estadual do Oeste do Paraná. Cascavel, 140 f., 2016.

DAL PICOL, Greyce. A morfossintaxe na oralidade do Vêneto Sul-Rio-Grandense: perfil dialetal de comunidades rurais da região da $4^{\mathrm{a}}$ Légua, Caxias do Sul/RS. Mestrado (em Letras e Cultura) - Faculdade de Letras, Universidade De Caxias Do Sul. Caxias do Sul, 122 f., 2013.

DE MARCO, Elizete Aparecida De. A trajetória e presença do talian e do dialeto trentino em Santa Catarina: por uma educação intercultural. Dissertação (Mestrado em Educação) - Centro de Ciências da Educação, Universidade Federal de Santa Catarina. Florianópolis, 2009.

FERRAZ, Aderlande Pereira. O panorama linguístico brasileiro: a coexistência de línguas minoritárias com o português. Filol. lingüíst. port., n. 9, p. 43-73, 2007.

FESTUGATTO, Marlene Maria. Interferências da língua talian no aprendizado do espanhol: um estudo de caso. Mestrado (em Letras) - Universidade Católica de Pelotas. Pelotas, 128 f., 2005 .

GUBERT, Antonio Luiz. Influências do italiano no português brasileiro de Vargeão (SC): um estudo sobre variação no nível fonético. Mestrado (em Letras) - Programa de Pós-Graduação em Letras, Universidade Federal do Paraná. Curitiba, 93 f., 2012. 
HASSELSTRON, Munick Maria. Línguas de imigração em contato com o português no oeste catarinense: crenças e atitudes linguísticas. Mestrado (em Estudos Linguísticos) - Programa de Pós-Graduação em Estudos Linguísticos, Universidade Federal da Fronteira Sul. Chapecó, 146 f., 2018.

HONORIO, Alessandra Regina Ribeiro. Descendentes de (i)talianos de Cascavel-PR: língua e cultura encobertas. Doutorado (em Letras, Língua, Literatura e Cultura Italianas) - Faculdade de Filosofia, Letras e Ciências Humanas, Universidade de São Paulo. São Paulo, 250 f., 2016.

LODI, Catiana Dallacort. Ghe zera una volta... O ensino de talian como língua adicional para crianças: uma proposta didática a partir da contação de história. Mestrado (em Letras) Instituto de Filosofia e Ciências Humanas, Fundação Universidade de Passo Fundo. Passo Fundo, 109 f., 2020.

LUZZATTO, Darcy Loss. Almanaque talian: arquitetura, culinária, cultura, história, histórias de antanho, os imigrantes e a religião, provérbios, citações e curiosidades. Pinto Bandeira: Edições Araucária, 2016.

MATOZO, Drieli Laiza. Crenças e atitudes linguísticas de ítalo-descendentes no contato português/talian: contexto urbano e rural de Chapecó-SC. Mestrado (em Estudos Linguísticos) - Programa de Pós-Graduação em Estudos Linguísticos, Universidade Federal da Fronteira Sul. Chapecó, 138 f., 2018.

MIAZZO, Georgia. Afinal, o que é "talian"? Revista Italiano UERJ. v. 2, n. 1. UERJ, Rio de Janeiro. p. 33-45, 2011.

MOMBELLI, Raquel. "Mi soi talian, gracia a Dio": Identidade étnica e separatismo no oeste catarinense. Mestrado (em Antropologia Social) - Centro de Filosofia e Ciências Humanas, Universidade Federal de Santa Catarina. Florianópolis, 135 f., 1996.

MONTRUL, Silvina. The Acquisition of Heritage Languages. Cambridge: Cambridge University Press, UK, 2016. https://doi.org/10.1017/CBO9781139030502

PANIZ, Silvio. A fonologia do talian, o vêneto-rio-grandense falado na cidade de Nova Roma Do Sul, sob a luz da teoria da otimidade. Mestrado (em Letras) - Universidade Católica de Pelotas. Pelotas, 178 f., 2005.

PERTILE, Marley Terezinha. $\mathbf{O}$ talian entre o italiano-padrão e o português brasileiro: manutenção e substituição lingüística no Alto Uruguai gaúcho. Doutorado (em Letras) Instituto de Letras, Universidade Federal do Rio Grande Do Sul. Porto Alegre, 248 f, 2009.

PIOVESAN, Almir Antonio. I piccoli signori: bilingüismo ítalo-português e apagamento do talian em Viadutos (RS). Mestrado (em Letras) - Instituto de Filosofia e Ciências Humanas, Fundação Universidade de Passo Fundo. Passo Fundo, 195 f., 2007. 
RIO GRANDE DO SUL. Lei $\mathbf{n}^{\mathbf{0}} \mathbf{1 3 . 1 7 8}$, de 10 de junho de 2009a. Declara integrante do patrimônio histórico e cultural do Estado o dialeto Talian, originado dos italianos e descendentes radicados no Rio Grande do Sul. Disponível em: http://www.al.rs.gov.br/filerepository/repLegis/ arquivos/13.178.pdf. Acesso em: 21 abr. 2021.

RIO GRANDE DO SUL. Lei $\mathbf{n}^{\mathbf{0}} \mathbf{2 6 1 5}$, de 13 de novembro de 2009b. Dispõe sobre a cooficialização da língua do talian - vêneto brasileiro, à língua portuguesa, no município de Serafina Corrêa - RS. Disponível em: https://leismunicipais.com.br/a/rs/s/serafina-correa/ lei-ordinaria/2009/262/2615/lei-ordinaria-n-2615-2009-dispoe-sobre-a-co-oficializacao-dalingua-do-talian-veneto-brasileiro-a-lingua-portuguesa-no-municipio-de-serafina-correa-rs. Acesso em: 16 maio 2021.

RODRIGUES, Sarah Loriato. Mi parlo taliàn: análise sociolinguística do bilinguismo português-dialeto italiano no município de Santa Teresa, ES. Mestrado (em Linguística) Centro de Ciências Humanas e Naturais, Universidade Federal Do Espírito Santo. Vitória, 206 f., 2015.

SANTA CATARINA. Lei $\mathbf{n}^{\mathbf{0}} \mathbf{1 4 . 9 5 1}$, de 11 de novembro de 2009. Declara integrante do patrimônio histórico e cultural do estado o dialeto "talian", originado dos italianos e descendentes radicados em Santa Catarina. Disponível em: https://leisestaduais.com.br/sc/lei-ordinaria-n-14951-2009santa-catarina-consolida-as-leis-que-dispoem-sobre-o-patrimonio-cultural-do-estado-desanta-catarina. Acesso em: 21 abr. 2021.

SCHOLL, Ana Paula. O conceito de translinguagem e suas implicações para os estudos sobre bilinguismo e multilinguismo. Revista Abralin, v. 19, n. 2, p. 1-5, 2020.

SERRAFINA CORRÊA. Processo de Co-Oficialização da Língua Talian, 2009. Disponível em: https:/www.serafinacorrea.rs.leg.br/leis/normas-juridicas/processo-de-co-oficializacao-dalingua-talian/view. Acesso em: 28 set. 2021.

SEVERO, Cristine Gorski. Política(s) linguística(s) e questões de poder. Alfa, São Paulo, 57 (2): 451-473, 2013. Disponível em: https://www.scielo.br/j/alfa/a/ YRbtMdqmCWxKjtn8SQWGmHj/?format=pdf\&lang=pt. Acesso em: 29 set. 2021.

TIBOLLA, Flávia Rosane Camillo. 'Me tocou virar tudo': cicatrizes discursivas em narrativas de descendentes de imigrantes italianos. Dissertação (Mestrado em Estudos Linguísticos) - Programa de Pós-Graduação em Estudos Linguísticos, Universidade Federal da Fronteira Sul. Chapecó, 121 f., 2014.

ZANELLA, Kênia. Relações entre turismo de experiência e patrimônio cultural imaterial: um estudo sobre as experiências memoráveis do filò talian. Mestrado (em Turismo e Hotelaria) Programa de Pós-Graduação em Turismo e Hotelaria, Universidade do Vale Do Itajaí. Balneário Camboriú, 173 f., 2017. 
ZORTEA, Tamires Regina. Marcadores discursivos do talian no programa radiofônico Un Pochetin Dela Itàlia em Caibi, Santa Catarina. Mestrado (em Estudos Linguísticos) - Programa de Pós-Graduação em Estudos Linguísticos, Universidade Federal da Fronteira Sul. Chapecó, 221 f., 2019.

Recebido para publicação em: 12 jul. 2021. Aceito para publicação em: 30 set. 2021. 